\title{
CORRESPONDENCE
}

\section{Badger vaccination}

SIR - It was noble of Mr Rees (Nature 9 July, p.104) to come to the defence of the Zuckerman report; however, my criticisms were of the report rather than the Ministry.

Mr Rees misreads my plea that some attention should be paid to vaccination of badgers, as advocacy of vaccination as the answer.

It is well known that BCG is one of the less effective vaccines in man, both in the percentage of the population protected, and in the type of protection afforded (infection is not prevented, it is merely limited). Reports have shown that protection can vary from $78 \%$ of the vaccinated (human) population at best to negligible responses at worst. However, protection of only some of the population is epidemiologically significant, and whilst protection may not be absolute it is of proven value in reducing the transmission to further individuals - the significant factor here. The epidemiological basis in controlling a disease is to reduce the number of individuals infected by each diseased animal in its lifetime to less than one. Therefore any means of reducing the number of susceptible individuals contacted by each infected badger will be of significance. (Gassing undoubtedly comes into this category).

Though attempts to vaccinate foxes orally (against rabies) have shown what problems there can be, badgers are well known among zoologists for the ease with which they will take quite considerable quantities of easily prepared oral baits. This has been used to advantage in a variety of ecological studies.

The degree of infection in some areas was also cited as a reason against vaccination, and whilst gassing may be the most effective approach in severely affected areas, it is nevertheless still the case that vaccination alone, if feasible, would have some positive effect. What does not appear to have been considered was the value of vaccination in less infected areas, or even ring-vaccination around those areas to be gassed (migration into cleared areas being a problem).

At this stage all conjecture is limited by the lack of knowledge. However, I must still regret that the report did not more positively specify research aims. I still believe vaccination to be one of these.

M.J. CHAPMAN

Easingwold,

York, UK

\section{White or brown?}

SIR - Concluding his review of two important books of contemporary scientific and medical interest on dietary fibre and health ${ }^{1}$, John Yudkin says "Let us by all means eat brown or wholemeal bread if we like it. But let us not delude ourselves that it will make us healthier or prolong our lives". This statement is not justified by the data available on the efficacy of dietary fibre in lowering disease risk. There may be useful effects of certain dietary fibres in preventing or ameliorating intestinal diseases in general, but this aspect is for others more expert to discuss ${ }^{2,3}$. We now comment on the scientific aspects of fibre use in relation to colon cancer.

Countries with a high incidence of atherosclerosis and coronary heart disease usually have a high incidence of colon cancer, and vice versa ${ }^{4-6}$. For example, Great Britain has a high incidence of both kinds of disease, the Japanese a low incidence. Finland is an exceptional country, exhibiting a high incidence, in fact among the highest in the world, of atherosclerosis and myocardial infarction; however, interestingly, their colon cancer incidence is only slightly higher than that of Japan, but much lower than the other Scandinavian countries 7.8 . Independent groups in the United States and Europe have investigated the underlying mechanism ${ }^{9,10}$. Detailed inquiry showed that the Finnish people consumed a diet not too different with regard to the amounts of most components, especially lipids and proteins, from those of people in New York or Copenhagen, so, by current concepts their diet and nutrition account for their high incidence of heart disease. However, the Finnish people also consumed rather large amounts of whole grain bread and other sources of cereal fibre, resulting in a stool bulk two to three times larger than those of the populations in New York or Copenhagen. At the level of metabolic epidemiology 9,10 specifically in relation to secondary bile acids which were demonstrated to be promoters in the carcinogenic process ${ }^{11}$, the people in Finland and New York showed the same total bile acid levels, as would be expected with similar lipid intakes. However, and importantly, because of the increased stool bulk in Finland, the concentrations of bile acids were much lower - similar to the concentration found in Japan. The Japanese level was that low, not because of high fibre intake, but because of low fat intake $\mathrm{e}^{12}$. Thus, the epidemiology was explained by metabolic biochemical approaches, and it was demonstrated through studies in man that cereal fibre accounted for a decreased risk of colon cancer in Finland. Furthermore, parallel studies showed that cereal fibres, particularly bran, could decrease the incidence of colon cancer in animal models ${ }^{13,14}$. The few instances where this was not so involved feeding the fibre during the period when carcinogen was administered, but not during the important promotion phase ${ }^{15}$, or when too high a level of carcinogen was administered, thus overwhelming the promotion phase where cereal fibre exerts its major protective role ${ }^{16}$.

To be sure, more research is necessary on the effect of diverse fibres, and in fact on the effect of other micronutrients. Unlike Yudkin, we believe that the present data base is adequate to conclude that brown or wholemeal bread with adequate fibre and other whole grain cereals, such as bran-containing breakfast cereals, are not only tasty but, indeed, have every chance of reducing the risk of colon cancer, a major type of cancer in the Western world. It is so easy to implement, and in fact would simply be a return to the situation prevailing before extensive milling of cereals removed much of the valuable fibre. Thus, adverse health effects owing to possible mineral imbalances are unlikely. The consequences in lowering the risk of colon cancer, possibly other intestinal disease and even early diabetes ${ }^{17,18}$ would be appreciable if not "dramatic". Please, Dr Yudkin, be objective.

J.H. WI-ISBUIRCER B.S. REDUY

\author{
American Health Foundation, \\ Naylor Dana Institute \\ for Disease Prevention, \\ Valhalla, New York, USA \\ 1. Yudkin, I. Nature 291, 173-174(1981) \\ Burkitt, D.P. \& Trowcll, H. . . (ed) Refined Carbohydrate \\ Foods and Diseases (Academic, I ondon, 1975) \\ 3. Buskit, D.P. Am. I. clin. Nutr. 34, 428-431 (1981) \\ 4. Blackburn, H. Prev. Med 8. 612-678 (1979).

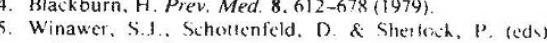 \\ Colorectal Cancer: Prevention, Epridemiology: and \\ Screening (Ka: en, New York, 1980) \\ 6. Turpeinen, (). Circulation 59, 1-7 (1979). \\ 7. Waterhousc, 1. Muir, (.. С (итеа, P. \& Powell, I \\ (cds) Cancer Incidence in Five Continents Vol. III \\ (Int. Union Against Canter. Berlin, 1976). \\ 8. Tcppo, 1. \& Saxen, E. Isruel I. med. Sci. 15, 322-328 \\ (1979).

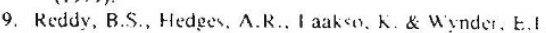 \\ Cancer 42, 2832-2838 (1978) \\ 10. IARC Intestinal Vicrociolog! Group Lanced ii, \\ 207-211 (1977). \\ 11. Reddy, B.S., (nhen, 1.A.. He(os, (i.1). Hill, P. \& \\ Weisburger, J.H. Adv. Cancer Res. 32, 237-245 (1980) \\ 12. Hirayama, T. Nutr. Cancer $1,67-81(1979)$ \\ 13. Keddy, B.S., Vori. 11. \& Nicolais, 11. J. natn. Cancer \\ Inst. 66, 553-557 (1981). \\ 14. Nigro, N.D., Bull. A.W.. Kloptfor, B.A., Pak, 11.S. \& \\ Campbell, K.I. J. natn. Cancer Inst. 62, 1097-1102 \\ (1979). \\ 15. Bauer, H.G., Asp. N.., (Oste, R., Dahlquist, A. \& Frediund. \\ P. Cancer Res. 39, 3752-3756 (1979). \\ 16. Cruse, J.P. I ewin, V.R. \& Clark, (C. Lancel ii \\ $1278-1280$ (1978). \\ 17. Lancet ii, $423-424$ (1981). \\ 18. Manhire, A., Henry, C. I ., Hartog, 11. \& Heaton, K. W \\ Lancet i, 1157 (1981).
}

\section{Yudkin's answer}

Sik - My article, to which Weisburger and Reddy refer, was a review of two recent publications, both entitled Medical Aspects of Dietary Fibre. One of these was a report of the Royal College of Physicians, which had this to say about fibre and colon cancer:

"There are reasonable grounds for the statement that, in genetically susceptible persons, large bowel cancer could be favoured by a fibre-depleted diet, but other explanations for the commonness of this cancer in Westernized countries are possible. Definite conclusions must await the identification of the carcinogen(s) and the study of environmental factors on its production."

As the references mentioned in the report make clear, the authors made at least as exhaustive a study of the literature as did Weisburger and Reddy in their letter; they also include the papers published by these workers.

The RCP authors, howcver, were clearly not as convinced that this evidence was conclusive as are your correspondents. In suggesting that I am not objective in my account of the role of dietary fibre in preventing colonic cancer. Weisburger and Reddy are really saying that the RCP itself was not objective when writing its report.

Joris Yeroh

London NW3, UK 